\title{
Transcription factors STAT-4, STAT-6 and CREB regulate Th1/Th2 response in leprosy patients: effect of $M$. leprae antigens
}

Rajni Upadhyay ${ }^{1}$, Bhavyata Dua ${ }^{1}$, Bhawna Sharma ${ }^{1}$, Mohan Natrajan², Ajai Kumar Jain³, Balaji Kithiganahalli Narayanaswamy ${ }^{4}$ and Beenu Joshi ${ }^{i^{*}}$ (D)

\begin{abstract}
Background: Leprosy is an ideal human disease to study $T$ cell regulation as patients show correlation between cytokine skewed Th1-Th2 responses and clinical forms of the disease. The Role of transcription factors on the modulation of Th1 and Th2 responses by $M$. leprae antigens has not been adequately studied. In the present study, we studied the effect of $M$. leprae antigens on transcription factors STAT-4, STAT-6 and CREB and their correlation with Th1/Th2 cell mediated immune responses in leprosy.

Methods: Leprosy patients of both categories of tuberculoid leprosy (BT/TT) and lepromatous leprosy (BL/LL) were selected from the OPD of NJ1L \& OMD, (ICMR), Agra and healthy individuals (H) were chosen from the staff and students working in the institute. Peripheral blood mononuclear cells (PBMCs) of the study subjects were stimulated with M. leprae antigens (WCL, MLSA, and PGL-1). Sandwich ELISA was done in the culture supernatants of healthy and leprosy patients to detect IL-4, IL-10 and IFN- $\gamma$. Further, expression of IFN- $\gamma$ and IL-4 and activation of STAT4, STAT6 and CREB transcription factors in $\mathrm{CD}^{+} \mathrm{T}$ cell with or without stimulation of $M$. leprae antigens was investigated by flow cytometry.

Results: Lepromatous leprosy patients showed significantly lower IFN- $\gamma$ and higher IL-4 levels in culture supernatant and significantly low expression of IFN- $\gamma$ and higher expression of IL-4 by CD4 ${ }^{+} \mathrm{T}$ cells than healthy individuals with or without antigenic stimulation. Antigenic stimulation significantly increased IL-10 in BL/LL patients but not in $\mathrm{BT} / \mathrm{TT}$ patients or healthy individuals. PGL-1 stimulation led to significantly higher activation of STAT-6 in BT/TT and $B L / L L$ patients in comparison to healthy individuals. All the three antigens led to activation of CREB in healthy and BT/TT patients but not in BL/LL patients.

Conclusion: Our findings show that $M$. leprae antigens differentially modulate activation of $\mathrm{T}$ cell transcription factors STAT-4/STAT-6 and CREB. These transcription factors are well known to regulate Th1 and Th2 mediated immune response which in turn could play vital role in the clinical manifestations of leprosy. These observations may help to determine how these $T$ cell transcription factors affect the development of immune dysfunction and whether these new pathways have a role in immunomodulation in intracellular diseases like leprosy and TB.
\end{abstract}

Keywords: Leprosy, Th1/Th2 cytokine, STAT-4, STAT-6, CREB

\footnotetext{
* Correspondence: beenuj2002@yahoo.co.in

'Department of Immunology, National JALMA Institute for Leprosy and

Other Mycobacterial Diseases (ICMR), Tajganj, Agra 282004, India

Full list of author information is available at the end of the article
}

(c) The Author(s). 2019 Open Access This article is distributed under the terms of the Creative Commons Attribution 4.0 International License (http://creativecommons.org/licenses/by/4.0/), which permits unrestricted use, distribution, and reproduction in any medium, provided you give appropriate credit to the original author(s) and the source, provide a link to the Creative Commons license, and indicate if changes were made. The Creative Commons Public Domain Dedication waiver (http://creativecommons.org/publicdomain/zero/1.0/) applies to the data made available in this article, unless otherwise stated. 


\section{Background}

The prevalence of leprosy at the end of 2017 was 192,713 cases worldwide and the number of new cases reported was 210,671. India still contributes the major percentage of leprosy cases due to continued transmission in the community [1]. The disease shows an interesting immunological phenomenon wherein the host immunity to Mycobacterium leprae ( $M$. leprae) dictates the clinical outcome of the disease. Patients with strong cell mediated responses are able to restrict the infection and are grouped into Tuberculoid type (TT) whereas, patients with low cell mediated immunity and high antibody response harbor numerous organisms and are categorized as Lepromatous type (LL). Leprosy has been an extensively studied human bacterial infection in terms of Th1/ Th2 immune responses. T helper (Th) cells are classified into Th1 and Th 2 cells based on the cytokines secreted by them [2]. Th1 cells predominantly secrete proinflammatory cytokines such as IFN- $\gamma$ whereas IL-4 and IL-10 cytokines are secreted by Th2 cells. IFN- $\gamma$ is a crucial cytokine for protection against mycobacterial infections including leprosy. Th1 type of immune response is characteristic of the tuberculoid form of leprosy; conversely, Th2 type immune response is dominant in the lepromatous form of leprosy.

A wide range of well defined transcription factors, including signal transducer and activator of transcriptions (STATs), T-bet, cyclic AMP (cAMP) responsive element binding (CREB) are known to shape the Th1/Th2 differentiation. Lineage commitment to Th1/Th2 is now better understood in terms of transcription factors. Inappropriate induction of Th1/Th2 cell plays an important role in the outcome of the disease. STAT-4 and STAT- 6 play important roles in regulating the differentiation of Th cell subsets. STAT-4 is an essential component of the IL-12 signaling pathway and plays an important role in Thl differentiation. Although STAT-4 is expressed both in Th1 and Th2 cells, STAT-4 can only be phosphorylated by IL-12 in Th1 cells as there is marked down-regulation of IL-12R $\beta$ specifically in Th2 cells [3]. However, little is known about the exact mechanism by which STAT-4 activation leads to Th1 differentiation. In contrast to STAT-4, STAT-6 plays a central role in modulating Th2 differentiation. Binding of IL-4 to the IL-4 receptor results in the phosphorylation and dimerization of STAT-6 [4]. Furthermore, CREB, a transcription factor which belongs to the family of basic leucine zipper (bZIP), binds to cAMP responsive element (CRE) and is essential for $\mathrm{T}$ cell function and cytokine production [5]. CREB plays various roles in immune function including its role in promoting anti-inflammatory immune responses through inhibition of $\mathrm{NF}-\mathrm{kB}$ activity, the induction of IL-10, and the generation of regulatory $\mathrm{T}$ cells. These anti-inflammatory responses could be protective by inhibiting unwanted inflammation, tissue damage, and autoimmune responses, or they could be pathogenic in the context of infection and tumor immunosurveillance [6].

Role of transcription factors on the modulation of immune responses in leprosy has not been thoroughly studied. Kim et al., have shown IL-12 induced STAT-4 phosphorylation and DNA binding in M. leprae-activated T cells in TT but not in LL patients [7]. Regulatory role of CREB in production of IFN- $\gamma$ is well documented in $M$. tuberculosis infection [8]. Therefore, in the present study we have studied $M$. leprae antigens mediated Th1/Th2 specific $\mathrm{T}$ cell transcription factors STAT-4, STAT-6, and CREB activation and cytokine production in leprosy patients and healthy individuals.

\section{Methods}

Study subjects

Leprosy patients of both the categories of tuberculoid leprosy (TT/BT) $(N=15)$ and lepromatous leprosy (BL/LL) $(N=9)$ were selected from the OPD of National JALMA 1nstitute for Leprosy \& OMD (ICMR), Agra (Age range $19-48$ yrs). Patients were diagnosed on the basis of clinical and bacteriological criteria and classified according to the immunological scale of Ridley-Jopling [9]. Twelve healthy individuals working in the laboratory were included as healthy controls. All the healthy individuals were clinically free from infections at the time of sample collection and had no history of TB and Leprosy. In addition, they were not contacts of patients, therefore, it is unlikely that they would be harboring the disease. Ten milliliter peripheral blood was collected in heparinized vials from all study subjects after taking informed written consent and the study was approved by institutional human ethics committee (Human Ethics Committee meeting of National JALMA 1nstitute for Leprosy \& OMD, Agra dated 21.2.2010).

\section{Antigens}

Mycobacterium leprae soluble antigen (MLSA), Whole cell lysate (WCL) and Phenolic glycolipid-1 (PGL-1) were procured from the laboratory of Dr. John T Belisle, Deptt of Microbiology, Immunology and Pathology, Colorado State University, (under WHO Contract Number USA NIH-NO1-AI-25469).

\section{Separation of peripheral blood mononuclear cells (PBMCs) from blood and antigenic stimulation}

PBMCs were isolated from buffy coats from healthy donors and leprosy patients (both tuberculoid and lepromatous) by density gradient centrifugation using Ficoll hypaque. Cells were incubated in RPMI-1640 supplemented with 5\% heat inactivated FBS (Hyclone, USA), $2 \mathrm{mML}$ - Glutamine, 100 unit penicillin $/ \mathrm{ml}$ and $100 \mu \mathrm{g}$ streptomycin/ml (Sigma, USA) at $37^{\circ} \mathrm{C}$ and $5 \%$ $\mathrm{CO} 2$ in a humidified incubator. Cells were stimulated 
with MLSA $(10 \mu \mathrm{g} / \mathrm{ml})$, WCL $(10 \mu \mathrm{g} / \mathrm{ml})$ and PGL-1 $(15 \mu \mathrm{g} / \mathrm{ml})$ for $24 \mathrm{~h}$. Antigen doses were standardized earlier in our laboratory for a previous study [10]. In brief, standardization of optimum dose of antigen was done by both MTT and LTT assay using PBMCs of healthy individuals. The optimum dose corresponds to the log phase of the curve generated by these assays.

\section{Sandwich ELISA}

Cytokine estimation was done in the culture supernatant of PBMCs of 15BT/TT, 9BL/LL and 12 healthy donors. Supernatants were collected from PBMC culture after $48 \mathrm{~h}$ for IL-4 and IL-10 estimation and after 5 days for IFN- $\gamma$ estimation. Detection of secreted cytokines was done by commercially available sandwich ELISA kits from R \& D systems, Minneapolis, USA.

\section{Flow cytometric analysis}

Effect of M. leprae antigens (MLSA, WCL, and PGL-1) on phosphorylated status of STAT-4, STAT-6 and CREB on $\mathrm{CD}_{4}^{+} \mathrm{T}$ cells and on frequency of IFN- $\gamma$, IL-4 producing $\mathrm{CD} 4^{+} \mathrm{T}$ was analysed by flow cytometry. In brief $2 \times$ $10^{6}$ cells $/ \mathrm{ml}$ were stimulated with standard doses of WCL, MLSA and PGL-1, few cells were kept without stimulation. Plates were incubated for $24 \mathrm{~h}$ at $37^{\circ} \mathrm{C}$ in $5 \% \mathrm{CO}_{2}$ with humidified air. Six hours before the termination of incubation, cells were treated with monensin $(4 \mu \mathrm{M}$, Sigma, USA). After incubation cells were stained with antibodies for surface markers - anti- human CD3 PE $\mathrm{Cy} 5$, anti- human CD4 FITC and were incubated for $30 \mathrm{~min}$ in dark at $4{ }^{\circ} \mathrm{C}$. Cells were then washed and fixed with $4 \%$ formaldehyde in phosphate buffer saline (PBS, $\mathrm{pH}-7.4$ ). Cells were permeabilized and staining was done for intracellular cytokines and transcription factors. Cells were stained with anti-human IL-4 APC, anti human IFN- $\gamma$ PE Cy7, antihuman pSTAT-4 PE, anti- human pSTAT-6 Alexa Flour 647 and anti -human pCREB Alexa Flour 647 and incubated for $30 \mathrm{~min}$ in dark at $4^{\circ} \mathrm{C}$. All the antibodies for flowcytometry were purchased from BD Biosciences, USA. Stained cells were acquired in BD FACS Aria (BD, San Hose, USA) and the percentage of cells was calculated using FACS Diva Software.

\section{Statistical analysis}

Statistical analysis was done using Prism 3 software (Graph pad version 3, LA Jolla, USA). Data was presented as mean \pm SEM. Variation between the groups was calculated by non parametric Mann Whitney test. $P$ value less than 0.05 was considered as significant. Values of stimulated PBMCs were normalised by subtracting the unstimulated values for comparison among different study subjects.

\section{Results}

$M$. leprae mediated secretion of $\mathrm{Th} 1 / \mathrm{Th} 2$ cytokines in the culture supernatant of PBMCs of leprosy patients and healthy individuals

PBMCs of leprosy patients (BT/TT, BL/LL) and healthy individuals $(\mathrm{H})$ were stimulated with $M$. leprae antigens (MLSA, WCL and PGL-1) and culture supernatants were collected after $48 \mathrm{~h}$ and 5 days. Secreted Th1 cytokine IFN- $\gamma$ and Th2 cytokines IL-4 and IL-10 were estimated in the supernatant.

In absence of antigens significantly higher production of IFN- $\gamma(p=0.027)$ was observed in culture supernatant of healthy individuals $(\mathrm{H})$ as compared to BL/LL patients (Fig. 1(I)A). IFN- $\gamma$ level was higher in response to MLSA, WCL and PGL-1 in culture supernatant of healthy individuals as compared to lepromatous patients and tuberculoid patients. However, no significant difference was noted among any groups in response to all three antigens (Fig. 1(I)B).

Significantly higher basal concentration of IL-4 ( $p=$ 0.026) was noted in lepromatous patients (Fig. 1(II)A) as compared to healthy individuals. MLSA significantly increased production of IL-4 in lepromatous patients and healthy individuals as compared to tuberculoid patients ( $p$ value $=0.048,0.0364$ respectively). On other hand, PGL-1 stimulation did not show any significant difference in IL-4 levels in healthy individuals and leprosy patients, but the lowest level of IL-4 was observed in healthy individuals (Fig. 1(II)B).

No difference was noted in IL-10 concentration among patients and healthy individuals in unstimulated PBMCs. Significant up regulation of IL-10 was observed post stimulation with MLSA and WCL in culture supernatant of lepromatous patients in comparison to tuberculoid patients $(p=0.014$ for MLSA, $p$ value $=0.009$ for $\mathrm{WCL}$ ) and healthy individuals $(p=0.003$ for MLSA, $p=0.013$ for WCL) (Fig. 1(III)A). Decreased secretion of IL-10 was observed after PGL-1 stimulation in healthy individuals and tuberculoid patients but the change was not significant as compared to lepromatous patients (Fig. 1(III)B). No difference in IL-10 production was noted in culture supernatant of healthy individuals and tuberculoid patients after MLSA and PGL-1 stimulation (Fig. 1(III)B).

\section{M. leprae antigens mediated expression of Th1 and Th2 cytokines, STAT and CREB transcription factors in $\mathrm{CD}^{+}{ }^{+} \mathrm{T}$ cells in leprosy patients and healthy individuals}

Interaction of $\mathrm{T}$ cell receptor with MHC/antigen complex leads to activation of naïve $\mathrm{T}$ cells and its differentiation to Th1 or Th2 cell type expressing IFN- $\gamma$ and IL- 4 cytokines respectively. Role of transcription factor STAT-4 in the induction of IFN- $\gamma$ by IL-12 has been suggested whereas differentiation of Th2 cells is mediated by STAT6. Transcription factor CREB plays diverse role in immune 


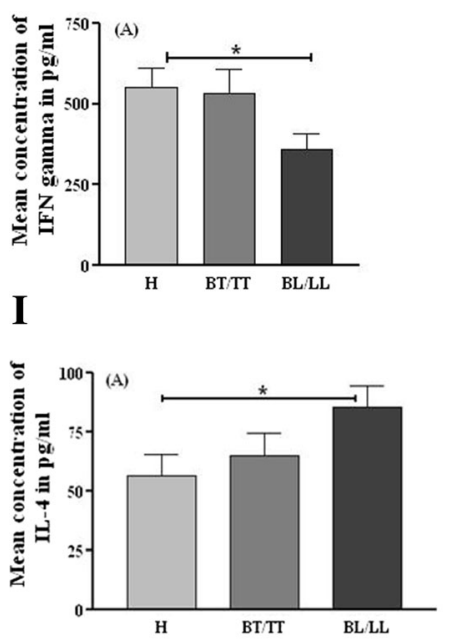

II

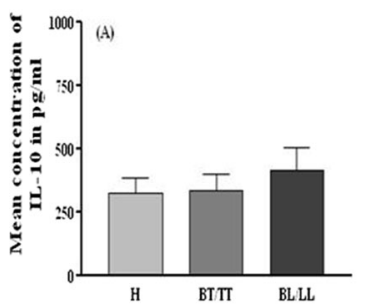

III
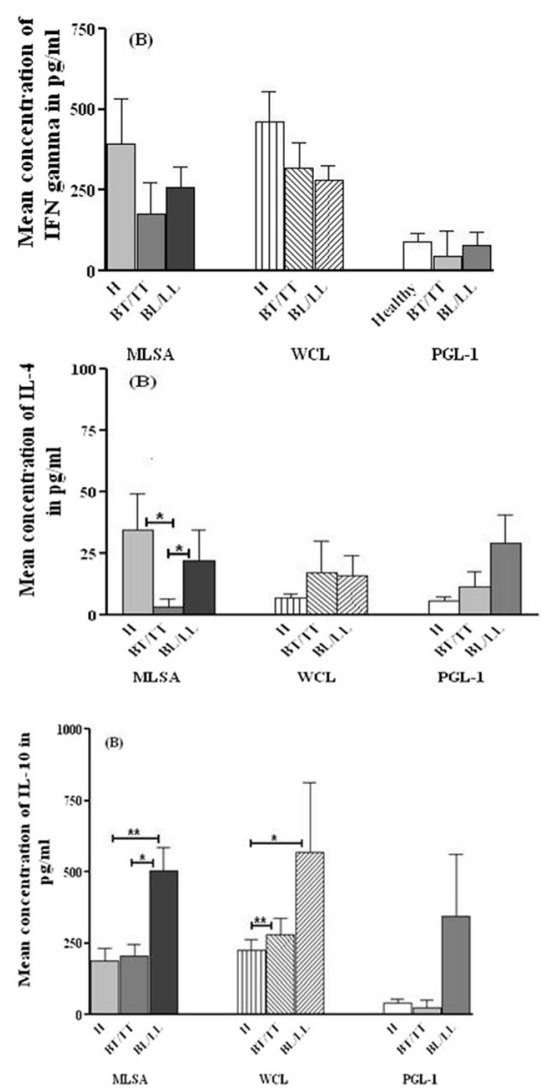

Fig. 1 Cytokine levels in culture supernatant of healthy and leprosy patients. Cytokine levels in culture supernatant of unstimulated (A) M. leprae antigens stimulated (B) PBMCs of healthy individuals (H), TT/BT and BL/LL patients. PBMCs from the study subjects were cultured with or without antigens for 5 days in RPMI at $37^{\circ} \mathrm{C}$ in $5 \%$ humidified atmosphere. Supernatants were collected after $48 \mathrm{~h}$ and 5 days of culture and cytokine was estimated. Concentration of cytokine was normalized after subtracting values of unstimulated supernatant from stimulated supernatant. I= IFN $\gamma$, $\mathbf{I I}=\mathrm{IL}-4, \mathbf{I I I}=\mid \mathrm{L}-10 .{ }^{*}=p<0.05,{ }^{* *}=p<0.001 . \mathrm{MLSA}-\mathrm{M}$. leprae soluble antigen, WCL- whole cell lysate, PGL-1- Phenolic glycolipid-1. BT/TT (Borderline tuberculoid/Tuberculoid), BL/LL (Borderline lepromatous/Lepromatous)

response. It regulates Th1, Th2 and Th17 type of immune response differentially. Therefore, expression of cytokines IFN- $\gamma$, IL-4 and transcription factors STAT-4, STAT-6 and CREB on $\mathrm{CD} 4^{+} \mathrm{T}$ cells with and without stimulation of MLSA, WCL and PGL-1 antigen was studied. PBMCs from leprosy patients and healthy individuals were stimulated with antigens and stained with fluorochrome conjugated anti-CD4 antibody to intracellular cytokines. Cells were acquired by flow cytometer. Analyzed results were presented as mean percentage of cytokines expressing $\mathrm{CD}^{+} \mathrm{T}$ cells in blood of healthy individuals and leprosy patients.

\section{Expression of IFN- $\gamma$ and IL-4 in $\mathrm{CD}^{+} T$ cells}

Leprosy patients showed significantly reduced IFN- $\gamma$ expressing $\mathrm{CD}^{+}{ }^{+} \mathrm{T}$ cells $(p=0.005$ for $\mathrm{BT} / \mathrm{TT}, p=0.0006$ for $\mathrm{BL} / \mathrm{LL}$ ) as compared to healthy individuals at basal level (Fig. 2(II)A). These cells were also significantly higher in healthy individuals than lepromatous patients in response to antigenic stimulation ( $p$ value $=0.002$ for MLSA, $p=0.0002$ for WCL, $p<0.0001$ for PGL-1) and tuberculoid leprosy patients also showed significantly higher frequencies of these cells in response to antigenic stimulation $(p=0.003$ for MLSA, $p=0.0001$ for WCL, $p<0.033$ for PGL-1) as compared to lepromatous patients (Fig. 2(II)B).

Basal mean percentage of IL-4 expressing $\mathrm{CD} 4^{+} \mathrm{T}$ cells was significantly higher $(p=0.0008)$ in PBMCs of lepromatous leprosy patients as compared to healthy individuals. Significantly higher IL-4 expressing $\mathrm{CD}^{+} \mathrm{T}$ cells were noted in LL patients after stimulation with MLSA in comparison to healthy and BT/TT patients whereas significant difference was observed in the expression of these cells in only BL/LL and BT/TT patients after stimulation with WCL and PGL-1 $(p=0.0057$ for MLSA, $p=0.0133$ for WCL, $p=0.0041$ for PGL-1) (Fig. 2(III)A \& B).

\section{Expression of phosphorylated STAT-4 and STAT-6 in $C D 4^{+} T$ cells}

Significantly higher pSTAT- 4 expression by $\mathrm{CD} 4^{+} \mathrm{T}$ cells was observed in healthy individuals $(p=0.046)$ and tuberculoid patients $(p=0.042)$ as compared to lepromatous 


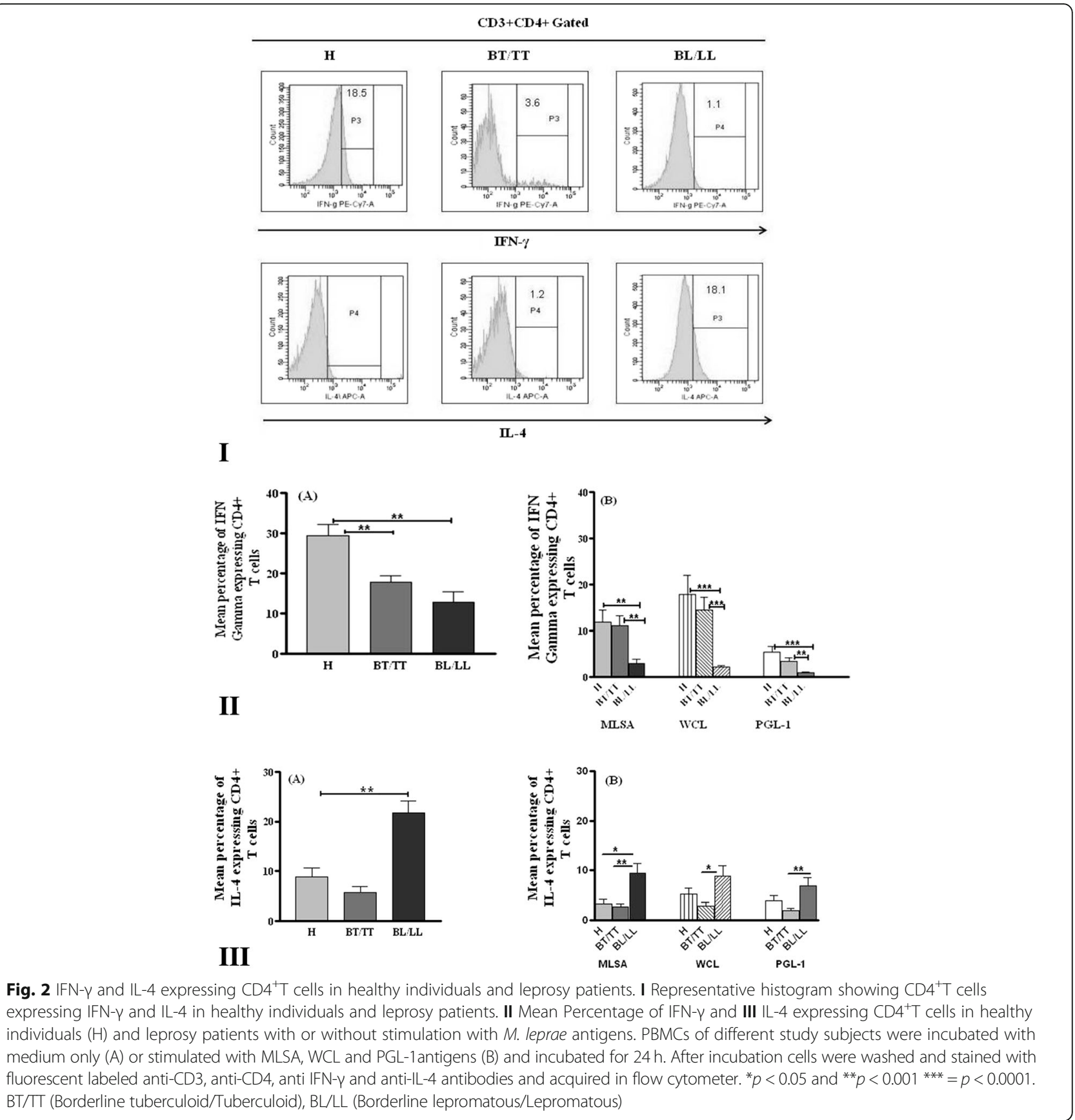

patients when no antigen was added. However, no difference was noted among various groups after antigenic stimulation (Fig. 3(II)A \& B).

Mean percentage of pSTAT-6 expressing $\mathrm{CD}^{+} \mathrm{T}$ cells was compared among leprosy patients and healthy individuals. Basal pSTAT-6 expression by $\mathrm{CD} 4^{+} \mathrm{T}$ cells was significantly higher in BL/LL and BT/TT patients both in comparison to healthy individuals $(p=0.0175$, 0.035 respectively) (Fig. 3(III)A). Further, no significant difference in pSTAT- 6 expression by $\mathrm{CD} 4^{+} \mathrm{T}$ cells was noted in healthy individuals, BL/LL and BT/TT patients when PBMCs were stimulated with MLSA however, higher pSTAT-6 expression was observed in BT/TT and BL/LL patients than healthy individuals. After WCL stimulation, significantly higher expression of pSTAT-6 by $\mathrm{CD} 4^{+} \mathrm{T}$ cells was noted in BT/TT patients $(p=0.0487)$ as compared to healthy individuals. BL/LL $(p=0.007)$ and BT/TT $(p=0.0487)$ patients showed significantly higher expression of STAT- 6 after PGL-1 stimulation when compared to healthy individuals (Fig. 3(III)B).

Ratio of mean percentages of basal and antigen mediated IFN- $\gamma$ and IL-4 expressing CD $4^{+} \mathrm{T}$ cells was significantly 


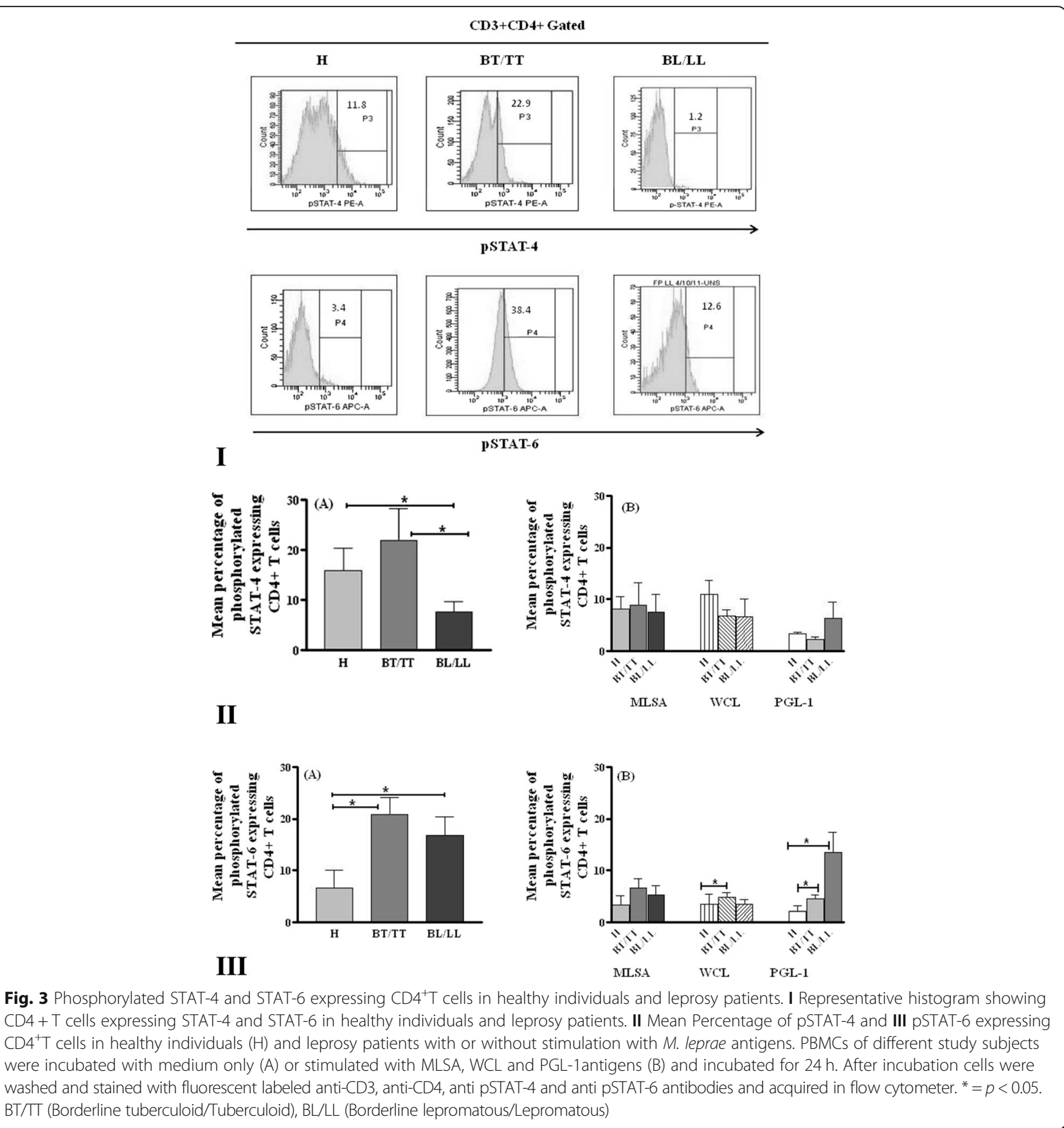

higher in healthy and BT/TT patients than BL/LL patients (Fig. 4(I)A \& B). However, significantly higher ratio of STAT4/STAT6 expressing CD4 ${ }^{+}$T cells was noted in unstimulated PBMCs in healthy individuals only as compared to $\mathrm{BL} / \mathrm{LL}$ patients and to both $\mathrm{BT} / \mathrm{TT}$ and $\mathrm{BL} / \mathrm{LL}$ patients in response to MLSA (Fig. 4(II)A \& B)

\section{Activation of CREB in $C D 4^{+} T$ cells}

Expression of activated transcription factor CREB which regulates proliferation and differentiation of $\mathrm{T}$ cells was also analyzed after antigenic stimulation. Basal expression of phosphorylated CREB by $\mathrm{CD}^{+}{ }^{+} \mathrm{T}$ cell was significantly higher $(p=0.0039)$ in PBMCs of healthy individuals and $\mathrm{BT} / \mathrm{TT}$ patients as compared to BL/LL patients (Fig. 5(II)A). Higher expression of pCREB by CD4 $4^{+} \mathrm{T}$ cells was also noted in healthy individuals and BT/TT patients as compared to lepromatous patients after MLSA, WCL and PGL-1 stimulation. However, significant difference was noted in healthy individuals and BL/LL patients only with PGL-1 ( $p=0.046)$ stimulation (Fig. 5(II)B). 

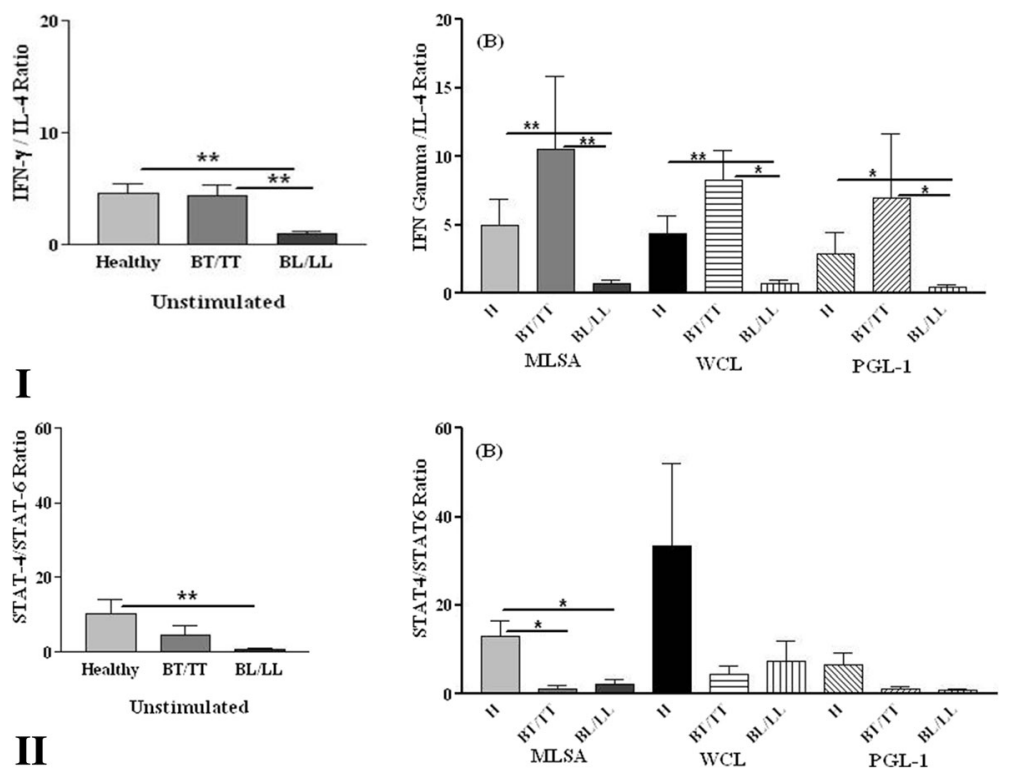

Fig. 4 Ratio of IFN- $-/ / L-4$, pSTAT4/pSTAT6 expressing CD4 ${ }^{+} T$ cells in healthy individuals and leprosy patients. Ratio of IFN- $\gamma /$ IL-4 (I), pSTAT4/pSTAT6 (II) expressing $C D 4^{+} T$ cells in healthy individuals $(\mathrm{H})$ and leprosy patients with or without stimulation with $M$. leprae antigens. ${ }^{*}=p<0.05$ and ${ }^{* *}=p<0.001$. BT/TT (Borderline tuberculoid/Tuberculoid), BL/LL (Borderline lepromatous/Lepromatous)

\section{Discussion}

In spite of several investigations, the mechanisms of $M$. leprae specific T cell anergy in LL patients are not well understood. This study has been done to correlate differential Th1/Th2 cell mediated immune responses observed in leprosy with known $\mathrm{T}$ cell transcription factors (STAT-4, STAT-6 and CREB) ex vivo along with the effect of $M$. leprae antigens (MLSA, WCL and PGL-1) on the modulation of these transcription factors.

Detection of Th1 cytokine IFN- $\gamma$ and Th2 cytokines IL-4 and IL-10 in the PBMCs confirmed Th1/Th2 polarization of immune response in leprosy patients. Significantly lower basal concentration of IFN- $\gamma$ was observed in culture supernatant of BL/LL patients than healthy individuals. When IFN- $\gamma$ production to different antigens was compared, no difference in the cytokine level was noted among all subject categories. This could be due to different cell populations namely, $\mathrm{CD} 4^{+} \mathrm{T}$ cells, NK cells and $\mathrm{CD} 8^{+} \mathrm{T}$ cells secreting the cytokines in the medium. It was also noticed that very low level of IFN- $\gamma$ was produced in response to PGL-1 in healthy individuals and in both types of leprosy patients. These observations confirm low immunogenicity of PGL-1. It also shows that IFN- $\gamma$ might be helping tuberculoid patients to restrict the $M$. leprae growth as IFN- $\gamma$ was significantly higher in BT/TT than BL/LL patients after stimulation with $M$. leprae antigens. Earlier similar observations were reported in studies done by Misra et al. [11]; Dockrell et al. [12] and Weir et al. [13].

Significantly higher basal level of Th2 cytokines IL-4 was observed in culture supernatant of lepromatous patients than healthy individuals and tuberculoid patients. After MLSA and WCL stimulation, levels of IL-4 were lower in tuberculoid patients than healthy individuals and BL/LL patients which is intriguing. However, it could suggest higher Th1 response in tuberculoid type of patients which may be due to the presence of well developed cell mediated immunity in tuberculoid patients that is directly related with $\mathrm{T}$ cell activation and differentiation. Highest production in IL-4 after PGL-1 stimulation is due to Th2 response exhibited by lepromatous patients as well as immunosuppressive nature of PGL-1. These findings show that PGL-1 might be responsible in inducing Th2 response which lowers Th1 response and help in bacterial growth which is seen in LL patients.

Expression of IFN- $\gamma$, IL-4 by $\mathrm{CD}^{+}{ }^{+} \mathrm{T}$ cells with and without stimulation of $M$. leprae antigen was also studied by flow cytometry in order to confirm observations noted by ELISA. Similar findings were noted in the case of both IFN- $\gamma$ and IL-4 secreting $\mathrm{CD} 4^{+} \mathrm{T}$ cells. Even more significance is found in flow cytometry data as compared to ELISA results because of its higher sensitivity and $\mathrm{T}$ cell specific cytokine secretion. Basal IFN- $\gamma$ level was significantly higher in healthy individuals than leprosy patients. However, all the three antigens induced increase in IFN- $\gamma$ expressing $\mathrm{CD} 4^{+} \mathrm{T}$ cells in healthy individuals and tuberculoid leprosy patients than in LL patients which is in contrast to findings observed by ELISA. In the culture supernatant several cells like $\mathrm{CD} 4^{+} \mathrm{T}$ cells, NK cells and $\mathrm{CD}^{+} \mathrm{T}$ cells are the source for IFN $\gamma$ production whereas in flow cytometry we have targeted specific cells, namely $\mathrm{CD} 4^{+} \mathrm{T}$ cells hence significant antigen specific response 


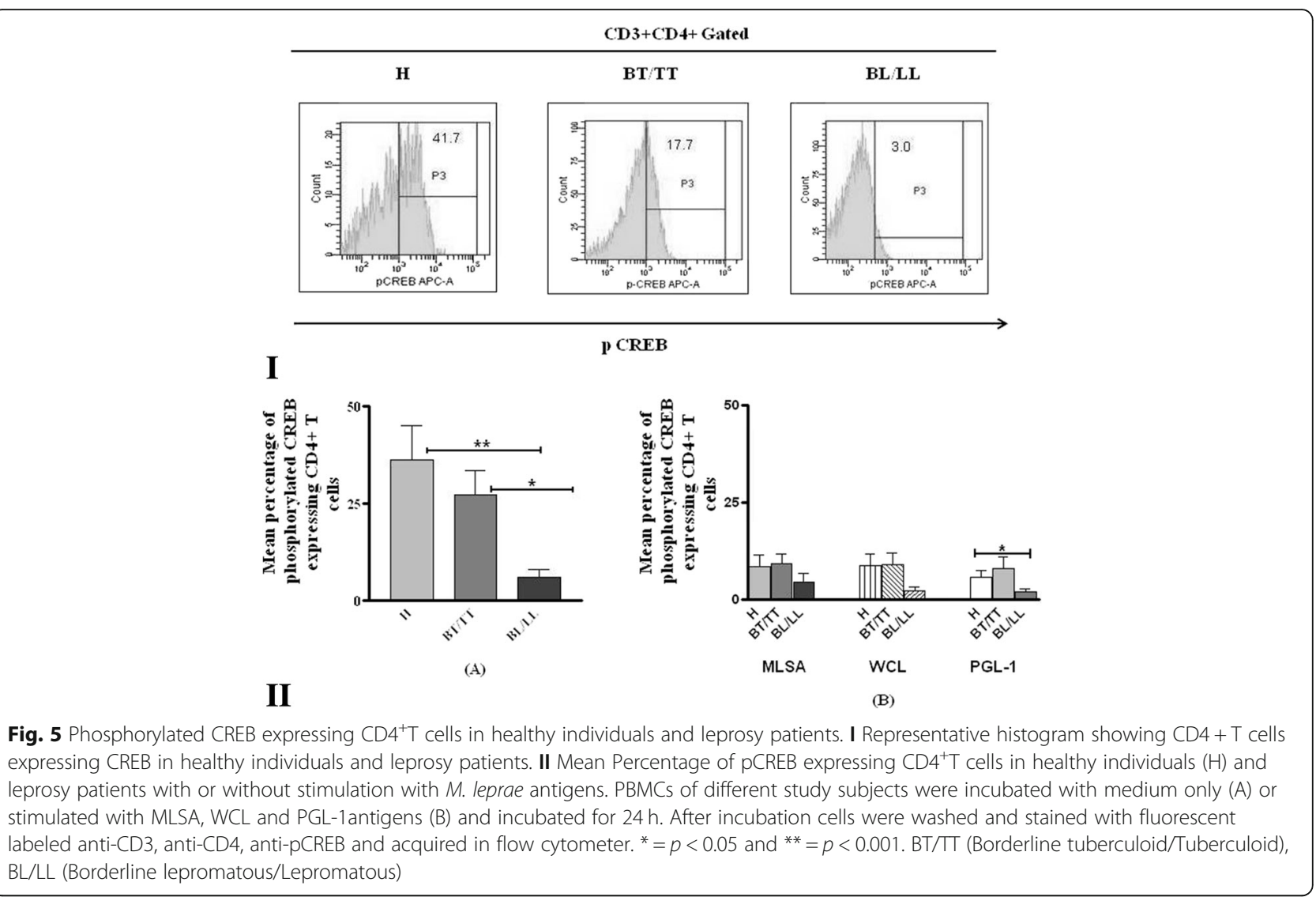

was observed. On the contrary, IL-4 expressing $\mathrm{CD} 4^{+} \mathrm{T}$ cells showed significantly higher mean percentage of these cells in BL/LL patients than healthy individuals and BT/TT patients. The study confirms Th2 type of response in the lepromatous pole and intact CMI showing Th1 response (high IFN- $\gamma$ and low IL-4) in TT/BT to $M$. leprae antigens. All of these results are in concordance with the findings of Misra et al. [11]; Dockrell et al. [12] and Weir et al. [13] which have shown strong Th1 response in tuberculoid patients and Th2 response and $\mathrm{T}$ cell unresponsiveness in lepromatous patients to $M$. leprae antigens. Dockrell et al., 1996 showed strong lymphoproliferative response and IFN- $\gamma$ secretion in response to fractionated cell wall or cytosol and membrane proteins of M. leprae in tuberculoid leprosy patients [12]. Our results are also in favor of other two studies done by our group earlier which states suppressive nature of $M$. leprae antigens MLSA, WCL and PGL-1 respectively in Jurkat T cells $[10,14]$.

As IL-10 can directly inhibit Th1 and Th2 cytokine production at the level of $\mathrm{T}$ cell $[15,16]$, this cytokine was also quantified in culture supernatants. All of three antigens induced an increase in IL-10 in BL/LL patients which was significantly higher than healthy individuals and BT/TT patients especially after MLSA and PGL-1 stimulation. Role of IL-10 in induction of phagocytic programme in macrophages but not triggering antimicrobial pathway in leprosy has been earlier reported. This leads to survival of mycobacteria leading to extensive disease in LL $[17,18]$. Inhibition of $M$. leprae specific T cell proliferation by IL-10 has been reported [19]. Boussiotis et al., 2000 also reported that increased susceptibility to mycobacterial infection is linked with secretion of IL-10 by T cells [20].

$\mathrm{T}$ cell transcription factors regulate specific immune response against pathogen after infection, hence we further studied the activation of different transcription factors STAT-4, STAT-6 after stimulation with M. leprae antigens. Role of these factors have not been studied widely in leprosy. Activation of STAT-4 is critical for Th1 differentiation and plays an important role in IL-12 signaling pathway. IL-12 receptor is composed of two $\beta$-like chains, IL- $12 R \beta 1$ and IL-12R $\beta 2$. IL-12R $\beta 2$ is selectively expressed on Th1 but not Th2 cells. IL-12R $\beta 2$ production and expression is limited to activated T-cells which respond to IL-12 by secreting IFN- $\gamma$ and is down-regulated by IL-4 and IL-10 [21]. In case of infection with intracellular pathogen development toward the Th1 subset is initiated by stimulation with IL-12 and IFN- $\gamma$, which are secreted by dendritic cells and macrophages. This Th1 differentiation is thus linked to activation of the transcription factors STAT-1 and STAT-4 downstream of 
IFN- $\gamma$ and IL-12 signaling, respectively. Together with the transcription factors such as nuclear factor of activated $\mathrm{T}$ cell (NFAT), adaptor related protein complex 1 (AP-1) and nuclear factor $\kappa B(\mathrm{NF} \kappa \mathrm{B})]$ that are activated by TCR engagement, STAT1 induces the expression of the master transcriptional factor of the Th1 subset, T-bet. Subsequently, STAT-4 and T-bet act coordinately to produce large amounts of IFN- $\gamma$ production in Th1 cells [22]. Higher basal levels of STAT-4 in healthy and BT/TT individuals in our study correlated with significant Th1 response in these individuals and may be responsible for their protective immunity which ultimately prevents the infection in healthy and restricts the same in BT/TT patients. Antigen specific activation of STAT-4 was not noted in our study which suggests that pathway other than STAT-4 could be involved in IFN $\gamma$ secretion in response to $M$. leprae antigens.

Expression and up-regulation of IL-12R $\beta 2$ in leprosy patients which is correlated with cell mediated immunity has been reported earlier by Kim et al. [7]. They reported IL-12 induced STAT-4 phosphorylation in tuberculoid but not in lepromatous patients after $M$. leprae stimulation. This is due to inability of the lepromatous patients to mount an appropriate Th response to $M$. leprae, which was also noted in our study showing low basal level of STAT4 activation. Watford et al., 2008 has identified one new STAT-4 target Map3K8 that has a rather different function [23]. Map3K8 is an upstream activator of ERK, which is inducible by IL-12 and T cell receptor-dependent signals. Chromatin immunoprecipitation assays have revealed that STAT-4 directly binds the Map3k8 gene. Deficiency of Map3k8 in T cells interferes with IFN- $\gamma$ production. Our group had earlier shown the inhibitory effects of $M$. leprae antigens on phosphorylation of MAPKs [10, 24]. Hence it is possible that M. leprae activates STAT-4 which leads to phosphorylation of MAPKs which is responsible for cytokine expression thereby killing of $M$. leprae. Deficiency of activation of STAT-4 or MAPKs may lead to low IFN- $\gamma$ which we have also shown, thereby leading to bacterial survival in LL.

STAT-6 is another important Th2 specific transcription factor. Binding of IL-4 receptor to IL-4 induces the phosphorylation of STAT-6 which further activates GATA-3. GATA-3 in return enhances the expression of Th2 cytokines IL-4, IL-5, IL-10 and IL-13 [25]. STAT-6 is not only implicated in the initiation of Th2 differentiation, but it also contributes to maintenance of the Th2 phenotype [4].GATA-3 also inhibits Stat4 transcription $[26,27]$ and directly represses Ifn- $\gamma[28]$. In our study we noted higher STAT- 6 expression in unstimulated PBMCs in patients in comparison to healthy individuals which correlated with higher Th1 response in healthy individuals and suggests role of this transcription factor in the development of disease. Further, significantly higher expression of STAT- 6 by $\mathrm{CD} 4^{+} \mathrm{T}$ cells in $\mathrm{BT} / \mathrm{TT}$ patients as compared to healthy individuals after WCL stimulation and in both $\mathrm{BL} / \mathrm{LL}$ and $\mathrm{BT} / \mathrm{TT}$ patients as compared to healthy individuals in response to PGL-1 also pinpoints role of STAT-6 in favoring of Th2 response and hence establishing infection. These findings also confirm role of PGL-1 in the immunosuppression seen in leprosy by evoking Th2 response through STAT-6 pathway.

CREB is a transcription factor that regulates diverse cellular responses, including proliferation and differentiation of T cells [29]. Liu et al., 2010 showed that CREB could promote the transcription and production of IFN- $\gamma$ through binding with the IFN- $\gamma$ proximal promoter [8]. The proximal IFN- $\gamma$ promoter contains CRE-like sequences (ACGT) where CREB binds and regulates IFN- $\gamma$ transcription. Although some studies on Jurkat T cells and transgenic mice suggest that CREB proteins inhibit the transcription of IFN- $\gamma[30,31]$, positive regulation by CREB of IFN- $\gamma$ production by $M$. tuberculosis responsive human $\mathrm{T}$ cells has been shown [32]. Reduced amounts of CREB binding to the IFN $-\gamma$ proximal promoter, and absence or diminished expression of phosphorylated CREB was reported in tuberculosis patients which in turn was responsible for reduced IFN- $\gamma$ production in TB patients $[8,32]$. We also observed similar finding in case of leprosy patients showing significantly higher basal expression of CREB in healthy individuals and BT/TT patients than BL/LL patients. It is inferred from this observation that cross regulatory pathways may be involved in the expression of IFN- $\gamma$ in leprosy patients as BT patients are able to restrict the $M$. leprae infection. CREB activation may be directly linked to Th 1 cells differentiation. Induction of CREB after $M$. leprae antigens stimulation also supports this fact.

\section{Conclusion}

Our study is an effort to investigate the correlation of $\mathrm{T}$ cell polarization observed in leprosy with the expression of transcription factors in a few leprosy patients. This study shows differential expression of $\mathrm{T}$ cell transcription factor STAT-4, STAT-6 and CREB in leprosy patients and healthy individuals correlating with Th1 and Th2 cytokine expression. Regulation of cell mediated immune response through transcription factors could play an important role in the clinical manifestation of leprosy. More detailed studies of expression profile of different transcription factor on large number of patients are needed to decipher the in vivo regulatory mechanism of $\mathrm{T}$ cell differentiation. These observations may provide new tools to study and monitor patients, to determine how these $\mathrm{T}$ cell transcription factors affect the development of immune dysfunction, and to study new pathways to block suppressor mechanisms. The findings may also help in better 
understanding of defects in cell mediated immunity in leprosy as well as other intracellular infections such as tuberculosis and leishmaniasis.

\begin{abstract}
Abbreviations
BL: Borderline lepromatous leprosy; BT: Borderline tuberculoid leprosy; CMI: Cell mediated immunity; CREB: Cyclic AMP responsive element binding protein; IL-12R: Interleukin 12 receptor; LL: Lepromatous lepromatous leprosy; LTT: Lymphocyte Transformation Test; MAPK: Mitogen activated protein kinase; MLSA: Mycobacterium leprae soluble antigen; MTT: 3-(4,5-Dimethylthiazol-2-yl)2,5-diphenyltetrazolium bromide; PBMC: Peripheral blood mononuclear cells; PGL: Phenolic glycolipid; PSTAT: Phosphorylated signal transducer and activator of transcription; STAT: Signal transducer and activator of transcription; TCR: T cell receptor; Th: T helper; TT: Tuberculoid tuberculoid leprosy; WCL: Whole cell lysate
\end{abstract}

\section{Acknowledgements}

Authors are thankful to ICMR for providing funds. RU and BD are supported by fellowship from ICMR. The support provided by technical staff Mr. M. Alam and Mr. Malikhan Singh Tomar, Mr. Brajendra Singh and staff of clinical division of National JALMA Institute of Leprosy and Other Mycobacterial Diseases, Agra is highly acknowledged.

All the persons who have contributed and helped in the manuscript have been acknowledged.

\section{Funding}

Funding was provided by Indian Council of Medical Research, New Delhi (No. 5/8/3(9)2009-ECD-1 (Main). Funding agency had no role in the design of the study and collection, analysis, and interpretation of data and in writing the manuscript.

\section{Availability of data and materials}

The data set generated and analysed during the current study are available with Corresponding author on reasonable request.

\section{Authors' contributions}

$\mathrm{RU}$ designed and performed the experiments, BD helped in sample collection, performing PBMC separation, BS helped in designing, performing and analysis of flow cytometry experiments, MN helped in selection of patients and provided the samples, AKJ supervised and helped in editing of manuscript, KNB helped in designing the study and editing of manuscript, B. designed and supervised the study and helped in writing the manuscript. All authors have read and approved the manuscript for submission.

\section{Ethics approval and consent to participate}

Study was approved by institutional human ethics committee of National JALMA Institute of leprosy \& OMD, Agra, India and informed consent of participants was taken

\section{Consent for publication}

Not Applicable.

\section{Competing interests}

The authors declare that they have no competing interests.

\section{Publisher's Note}

Springer Nature remains neutral with regard to jurisdictional claims in published maps and institutional affiliations.

\section{Author details}

'Department of Immunology, National JALMA Institute for Leprosy and Other Mycobacterial Diseases (ICMR), Tajganj, Agra 282004, India. ${ }^{2}$ Clinical Division, National JALMA Institute for Leprosy \& OMD, Tajganj, Agra 282004, India. ${ }^{3}$ Department of Zoology, Jiwaji University, Gwalior, Madhya Pradesh 474001, India. ${ }^{4}$ Department of Microbiology and Cell Biology, Indian Institute of Science, Bangaluru, India.
Received: 13 April 2018 Accepted: 7 December 2018

Published online: 14 January 2019

\section{References}

1. World Health Organisation (WHO). Global leprosy update, 2017: reducing the disease burden due to leprosy. Wkly Epidemiol Rec. 2018;93(35):445-56.

2. Mosmann TR, Cherwinski H, Bond MW, Giedlin MA, Coffman RL. Two types of murine helper $T$ cell clone. I. Definition according to profiles of lymphokine activities and secreted proteins. J Immunol. 1986;136:2348-57.

3. Szabo SJ, Dighe AS, Gubler U, Murphy KM. Regulation of the interleukin (IL)12Rß-2 subunit expression in developing Thelper 1 (Th1) and Th2 cells. J Exp Med. 1997;185:817-24

4. Goenka S, Kaplan MH. Transcriptional regulation by STAT6. Immunol Res. 2011;50:87-96

5. Yu CWYL, Lee SF. CREB is one component of the binding complex of the Ces-2/E2A-HLF binding element and is an integral part of the interleukin-3 survival signal. Mol Cell Biol. 2001;21:4636-46.

6. Wen AY, Sakamoto KM, Miller LS. The role of the transcription factor CREB in immune function. J Immunol. 2010;185:6413-9.

7. Kim J, Uyemura K, Van Dyke MK, Legaspi AJ, Rea TH, Shuai K, Modlin RL. A role for $\mathrm{IL}-12$ receptor expression and signal transduction in host defense in leprosy. J Immunol. 2001;167:779-86.

8. Liu Y, Guo YL, Zhou SJ, Liu F, Du FJ, Zheng XJ, Jia HY, Zhang ZD. CREB is a positive transcriptional regulator of gamma interferon in latent but not active tuberculosis infections. Clin Vaccine Immunol. 2010;17:1377-80.

9. Ridley DS, Jopling WH. Classification of leprosy according to immunity. Int J Lepr Other Mycobact Dis. 1966;34:255-73.

10. Dagur PK, Sharma P, Kumar G, Khan NA, Katoch VM, Sengupta U, Joshi B. Mycobacterial antigen(s) induce anergy by altering TCR- and TCR/CD28induced signalling events: insights into T-cell unresponsiveness in leprosy. Mol Immunol. 2009;47:943-52.

11. Misra N, Murtaza A, Walker B, Narayan PS, Misra RS, Armes V, Singh S, Colston J, Nath I. Cytokine profile of circulating $T$ cells of leprosy patients reflect both indiscriminate and polarized T-helper phenotype is stable and influenced by related antigens of Mycobacterium leprae. Immunology. 1995: 86:97-103.

12. Dockrell HM, Young SK, Britton K, Brennan PJ, Rivoire B, Waters MF, Lucas SB, Shahid F, Dojki M, Chiang TJ, Ehsan Q, McAdam KP, Hussain R. Induction of Th1 cytokine responses by mycobacterial antigens in leprosy. Infect Immun. 1996;64:4385-9.

13. Weir RE, Brennan PJ, Butlin CR, Dockrell HM. Use of a whole blood assay to evaluate in vitro $T$ cell responses to new leprosy skin test antigens in leprosy patients and healthy subjects. Clin Exp Immunol. 1999;116:263-9.

14. Dagur PK, Sharma B, Upadhyay R, Dua B, Rizvi A, Khan NA, Katoch VM, Sengupta U, Joshi B. Phenolic-glycolipid-1 and lipoarabinomannan preferentially modulate TCR- and CD28-triggered proximal biochemical events, leading to T-cell unresponsiveness in mycobacterial diseases. Lipids Health Dis. 2012;11:119-29.

15. de Waal Malefyt R, Abrams J, Bennett B, Figdor CG, de Vries JE. Interleukin 10 inhibits cytokine synthesis by human monocytes: an autoregulatory role of IL-10 produced by monocytes. J Exp Med. 1991;174:1209-20.

16. Schandene L, Alonso-Vega C, Willems F, Gerard C, Delvaux A, Velu T, Devos R, de Boer M, Goldman M. B7/CD28-dependent IL-5 production by human resting T cells is inhibited by IL-10. J Immunol. 1994;152:4368-74.

17. Bleharski JR, Li H, Meinken C, Graeber TG, Ochoa MT, Yamamura M, Burdick A, Sarno EN, Wagner M, Rollinghoff M, et al. Use of genetic profiling in leprosy to discriminate clinical forms of the disease. Science. 2003;301:1527-30.

18. Mosser DM, Edwards JP. Exploring the full spectrum of macrophage activation. Nat Rev Immunol. 2008:8:958-69.

19. Sieling PA, Abrams JS, Yamamura M, Salgame P, Bloom BR, Rea TH, Modlin RL. Immunosuppressive roles for IL-10 and IL-4 in human infection. In vitro modulation of T cell responses in leprosy. J Immunol. 1993;150:5501-10.

20. Boussiotis VA, Tsai EY, Yunis EJ, Thim S, Delgado JC, Dascher CC, Berezovskaya A, Rousset D, Reynes JM, Goldfeld AE. IL-10-producing T cells suppress immune responses in anergic tuberculosis patients. J Clin Invest. 2000;105:1317-25

21. Kaplan MH, Sun YL, Hoey T, Grusby MJ. Impaired IL-12 responses and enhanced development of Th2 cells in Stat4-deficient mice. Nature. 1996:382:174-7.

22. Djuretic IM, Levanon D, Negreanu V, Groner Y, Rao A, Ansel KM. Transcription factors T-bet and Runx3 cooperate to activate IFN- $\gamma$ and silence IL-4 in T helper type 1 cells. Nat Immunol. 2007;8:145-53. 
23. Watford WT, Hissong BD, Durant LR, Yamane H, Muul LM, Kanno Y, Tato CM, Ramos HL, Berger AE, Mielke L, Pesu M, Solomon B, Frucht DM, Paul WE, Sher A, Jankovic D, Tsichlis PN, O'Shea JJ. Tpl2 kinase regulates T cell interferon-gamma production and host resistance to toxoplasma gondii. J Exp Med. 2008;205:2803-12.

24. Joshi B, Kedouchi S, Dagur PK, et al. On cell signalling mechanism of Mycobacterium leprae soluble antigen (MLSA) in Jurkat T cells. Mol Cell Biochem. 2006;287:157-64.

25. Scheinman EJ, Avni O. Transcriptional regulation of GATA3 in Thelper cells by the integrated activities of transcription factors downstream of the interleukin-4 receptor and T cell receptor. J Biol Chem. 2009;284:3037-48.

26. Ouyang W, Ranganath SH, Weindel K, Bhattacharya D, Murphy TL, Sha WC Murphy KM. Inhibition of th1 development mediated by GATA-3 through an il-4-independent mechanism. Immunity. 1998;9:745-55.

27. Usui T, Nishikomori R, Kitani A, Strober W. GATA-3 suppress Th1 development by down regulation of STAT4 and not through effects on IL12Rß2 chain or T-bet. Immunity. 2003;18:415-28.

28. Chang S, Aune TM. Dynamic changes in histone-methylation 'marks' across the locus encoding interferon-gamma during the differentiation of T helper type 2 cells. Nat Immunol. 2007;8:723-31.

29. Mayr B, Montminy M. Transcriptional regulation by the phosphorylationdependent factor CREB. Nat Rev Mol Cell Biol. 2001;2:599-09.

30. Penix A, Gupta S, Gollob K, Garfein E, Coffman RL, Schindler C, Rothman P. Lack of interferon gamma receptor beta chain and the prevention of interferon gamma signaling in TH1 cells. Science. 1995;269:245-7.

31. Zhang F, Wang DZ, Boothby M, Penix L, Flavell RA, Aune TM. Regulation of the activity of IFN-gamma promoter elements during Th cell differentiation. J Immunol. 1998;161:6105-12.

32. Samten B, Howard ST, Weis SE, Wu S, Shams H, Townsend JT, Safi H, Barnes PF. Cyclic AMP response element-binding protein positively regulates production of IFN- $\gamma$ by T cells in response to a microbial pathogen. J Immunol. 2005;174:6357-63.

Ready to submit your research? Choose BMC and benefit from:

- fast, convenient online submission

- thorough peer review by experienced researchers in your field

- rapid publication on acceptance

- support for research data, including large and complex data types

- gold Open Access which fosters wider collaboration and increased citations

- maximum visibility for your research: over $100 \mathrm{M}$ website views per year

At $\mathrm{BMC}$, research is always in progress.

Learn more biomedcentral.com/submissions 